\title{
Research on Supply Chain Optimization of a T Enterprise Based on the Simulation Analysis of Subject Behavior
}

\author{
Haodong Lu ${ }^{1, \mathrm{a}}$, JiaQi Li ${ }^{1, \mathrm{~b}}$, Hongyu Shao ${ }^{1, \mathrm{c}^{*}}$, Yongliang Chen ${ }^{1, \mathrm{~d}}$ \\ ${ }^{1}$ School of Mechanical Engineering, Tianjin University, Tianjin 300354, China
}

\begin{abstract}
The manufacturing of the automobile industry is highly dependent on market demand. Therefore, the impact of changes in demand on the supply chain is worthy of attention. This article considers the application of flexible production management to the supply chain of the automobile industry. Simulation analysis research analyzes the overall impact of the differences in the behavior of different entities in the supply chain on the overall supply chain. By examining the possible consequences of these impacts, it provides targeted supply chain optimization suggestions and measures to promote the continuous optimization and development of the enterprise supply chain .
\end{abstract}

\section{Introduction}

The automobile industry is an important pillar industry of China's national economy. It is an industrial sector with high input, high output and cluster development. As an extremely large industry, with the automobile industry as the forerunner, a series of industrial clusters are formed. From the perspective of production, a car is an assembly product, which is assembled by a large number of parts (more than 20,000 pieces). In addition to the importance of economic benefits, the development of supply chain management in the automotive industry has also attracted much attention. Due to the extensive implementation of lean production, the automotive industry adopts just-in-time supply, the requirements of the supply chain are very high, and the supply chain management is relatively complex and refined.

Creating a lean and flexible business implementation process, shortening the time of each link in the value chain, reducing costs, improving production flexibility and management accuracy, and meeting the diversified needs of customers are the common goals pursued by the automotive industry supply chain.

Supply chain management has attracted the attention of relevant personnel at home and abroad since it was proposed. Shihua Ma (2000) discussed the status of core enterprises in the operation of the supply chain, from the influence of core enterprises in the industry, product development capabilities and product-oriented capabilities, business reputation and spirit of cooperation, leading product structure, management ideas, etc. The influence of core companies on the formation of strategic partnerships in the supply chain is studied [1]. Hu Kaishun (2003) put forward the structural model of the dynamic alliance supply chain, and gave the alliance form with the assembly unit as the core, the procurement chain, the collaboration chain and the internal chain [2].
Xiaoliang Li (Hau L. Lee, 2004) and others believe that the bullwhip effect is considered to be one of the forces that lead to the paralysis of the supply chain. They analyzed the four sources of the bullwhip effect and discussed how to reduce the harmful impact of the bullwhip effect on supply chain management [3]. Wendan Zhao and Dingwei Wang (2010) established a three-level supply chain model based on the MATLAB/Simulink environment and discussed the adjustment methods of supply chain management strategies in the case of commodity transportation delays [4]. Xu Chao (2019) studied the collaborative procurement negotiation strategy of cluster supply chain based on multi-agent [5]. Xue Ying (2012) analyzed the problems of inventory control in supply chain operation [6]. Yao Jianming (2013) conducted an in-depth study on supply chain planning and scheduling, described in detail the basic operating characteristics of supply chain scheduling under mass customization, and proposed the basic principles of supply chain dynamic scheduling under mass customization [7]. Amin Aalaei (2017) proposed a supply chain mathematical model with labor distribution function. The model takes into account the characteristics of the manufacturing industry, and minimizes the total holding cost of fixed assets, the cost of material handling between units, the cost of external transportation, and the cost of production. Fixed costs and labor wages for parts [8]. Behnam Karimi (2018) designed a multi-commodity multi-mode supply chain network for intelligent manufacturing [9]. Antonio A.C. Vieira (2019) et al. proposed a hybrid model that uses data for data warehouse, statistical distribution, or a combination of the two [10].

Looking at the research on supply chain management at home and abroad, there are few studies on the impact of demand changes on the supply chain. Considering the current dynamic and changeable market environment

\footnotetext{
* Corresponding author: shaohongyu@,tju.edu.cn

ahaodonglu1023@163.com, ${ }^{\mathrm{d}}$ chenyongliang@tju.edu.cn
} 
and demand changes, existing work studies have combined soft production management with supply chain management. On the basis of, through the modeling of the behavior of different subjects in the supply chain, the overall impact of the differences in the behavior of the subjects on the supply chain management is investigated, and corresponding analysis is made to guide the continuous optimization and development of the automotive supply chain.

\section{Methodology}

\subsection{The Methodology of the Behavior Simulation of Supply Chain Agents}

Based on the current fierce market competition environment, suppliers have partial substitution and complementary relations with each other, and customers also have multiple choices. Set the supply chain simulation environment as perfect competition in a single category market. With enterprise $\mathrm{T}$ as a fixed intermediate node, different random subject behaviors are set for suppliers and customers, such as customer A's preference for product quality. When the product qualification rate of enterprise $\mathrm{T}$ is lower than the expected value, it will reduce the satisfaction with enterprise $\mathrm{T}$, or even exit the current single Market transactions. Another situation is that if supplier B's financial indicators are good but the order delivery rate and product qualification rate indicators are too low, enterprise T's satisfaction with supplier B will be reduced due to customer satisfaction considerations, and supplier B will gradually withdraw this competitive market.

Considering the supply chain analysis and evaluation index system of Weichai Power determined by the research group in 2007 and the performance index index of BICCs (some leading and industry-leading companies) drawn up by PMG, comprehensively considering multiple aspects, the company's supply chain suppliers and the customer's subjective behavior simulation indicators are drawn up as follows:

- Basic information indicators: company size, listing status, company distance,

- Financial indicators: inventory turnover rate, return on net assets,

- Market indicators: customer satisfaction,

- Internal indicators: order delivery rate, urgent order completion rate, total supply chain management cost,

- External indicators: product qualification rate.

Add the evaluation index to the simulation program as shown below:

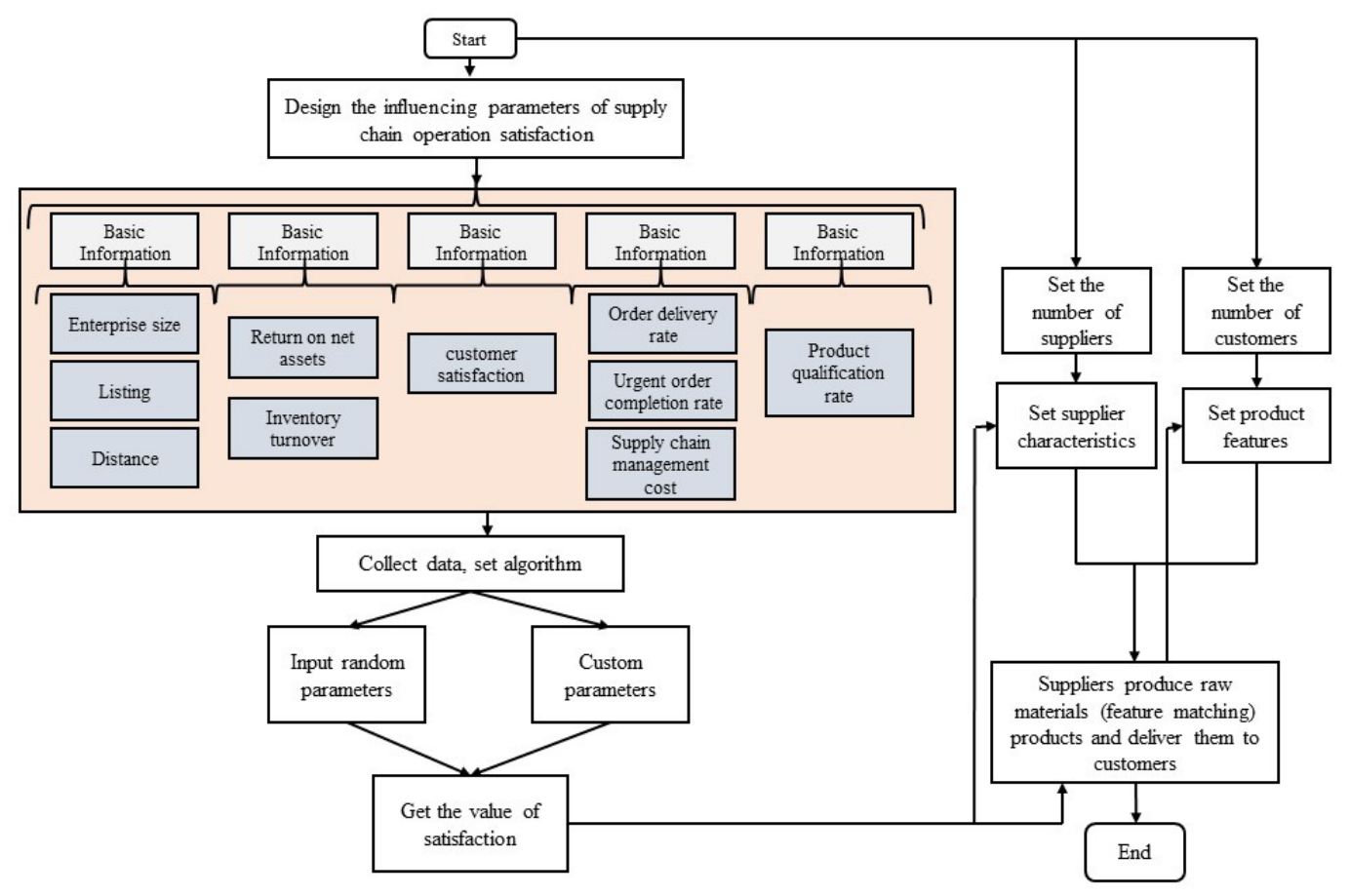

Fig. 1. Simulation model of subject behavior.

\subsection{Design of Simulation Algorithm for Subject Behavior of Supply Chain Based on NetLogo}

Suppose there are the following actual business scenarios in reality: there are several suppliers and customers in the market, and enter the supply chain to choose. After a period of time, with the change of satisfaction, the suppliers and customers with high satisfaction exist for a long time, and the customers with less than zero satisfaction leave the market. The model is established to simulate the operation of supply chain under different parameters. Based on the multi-agent simulation software Netlog, the design algorithm is as follows:

(1) Initialization interface (setup)

The first step: Set the size of the patch interface to an appropriate value to facilitate the simulation of the market environment.

The second step: initialize the block, set supplier and customer graphics, generate suppliers and customers 
according to the number set by the slider, and randomly generate the satisfaction of each supplier and customer in the market according to the normal distribution of mean 80 and variance 10.

(2) Run (go)

Step 3: set up the market mechanism and stop the operation when the number of customers drops to 0 .

Step 4: command the supplier to walk randomly in the panel interface, judge the supplier's relevant indicators, and command the increase or decrease of satisfaction. Order suppliers to randomly walk in customers, judge the relevant indicators of the market, order the increase or decrease of satisfaction.

Step 5: when the supplier moves to the small block whose market is empty, the raw materials are transferred to the enterprise $\mathrm{T}$, and the enterprise $t$ produces the product, so that the color of the small block (blue) changes to the corresponding color of the product (green, red, etc.), and the enterprise t's satisfaction with the supplier increases. If the small block already exists, the supplier is ordered to continue to move.

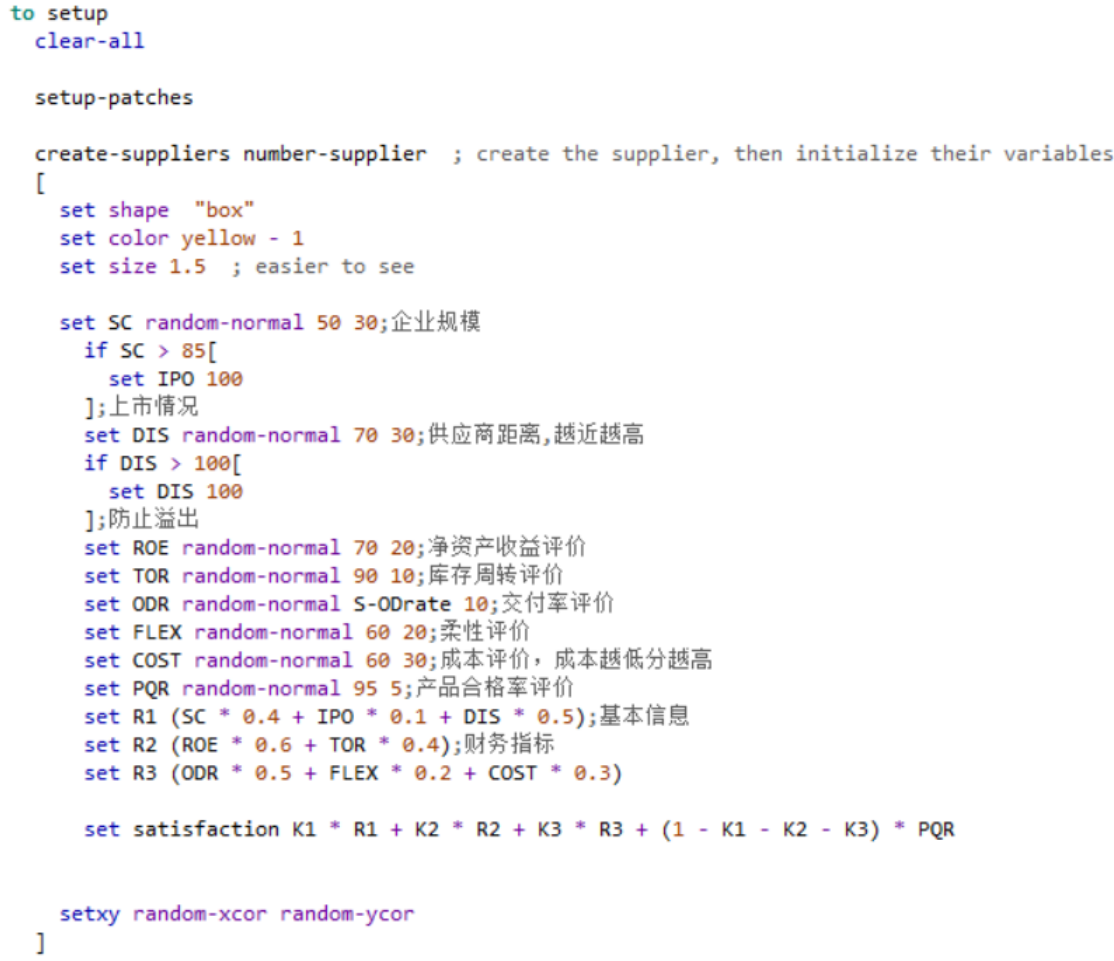

Fig. 2. Partial code display.

The initialization result of the simulation program is shown in Figure 3:

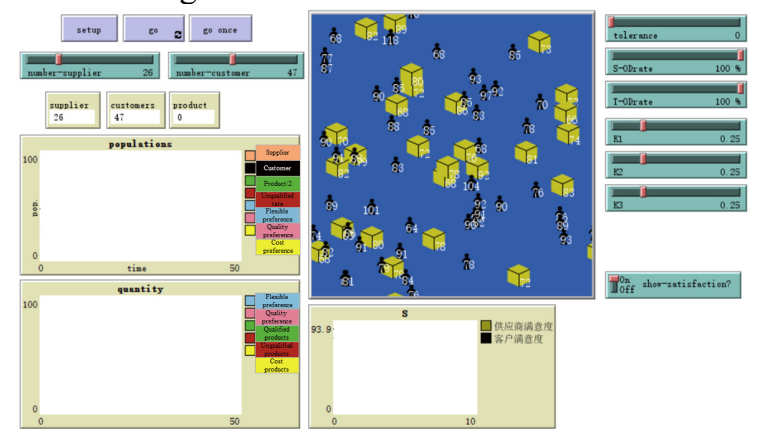

Fig. 3. Initialization interface.
Step 6: when the customer moves to a small insert with a product, judge whether the product type meets the customer's requirements. If yes, the customer's satisfaction will increase; if the product is unqualified, the customer's satisfaction will decrease; if the product is not the type required by the customer, the customer will continue to move.

Step 7: repeat step 5 and step 6 until the order stops or the number of customers drops to 0 .

(3) Do plots

Step 8: draw two lines to represent the quantity of suppliers and customers respectively; then draw $\mathrm{n}+1$ lines to represent the quantity of ordinary products and $\mathrm{N}$ kinds of other products respectively, once for each tick.

(4) Display labels

Step 9: set the satisfaction display switch. Turn on the switch to monitor the satisfaction of each supplier and customer, or turn off the switch to not show their satisfaction.

Some code screenshots are shown in Figure 2. 


\begin{tabular}{|c|c|c|}
\hline $\mathrm{r}$ & & \\
\hline $\begin{array}{l}\text { numbe } \\
\text { r- } \\
\text { custom } \\
\text { er }\end{array}$ & $\begin{array}{l}\text { Adjust the number of customers in } \\
\text { the simulation }\end{array}$ & $(0,100)$ \\
\hline $\begin{array}{c}\text { toleran } \\
\text { ce }\end{array}$ & $\begin{array}{l}\text { Adjust the tolerance of suppliers } \\
\text { and customers in the simulation. } \\
\text { The higher the tolerance value is, } \\
\text { the suppliers are more inclined to } \\
\text { produce non-conforming products }\end{array}$ & $(0,10)$ \\
\hline $\begin{array}{c}\text { S- } \\
\text { ODrate }\end{array}$ & $\begin{array}{l}\text { Adjust the delivery rate of supplier's } \\
\text { raw material order in simulation }\end{array}$ & $(0,100 \%)$ \\
\hline $\begin{array}{c}\text { T- } \\
\text { ODrate }\end{array}$ & $\begin{array}{l}\text { Adjust the order delivery rate of } \\
\text { enterprise } t \text { in simulation }\end{array}$ & $(0,100 \%)$ \\
\hline K1 & $\begin{array}{l}\text { Adjust the influence degree of the } \\
\text { supplier's enterprise basic } \\
\text { information index R1 in the } \\
\text { simulation }\end{array}$ & $(0,1)$ \\
\hline K2 & $\begin{array}{l}\text { Adjust the influence degree of the } \\
\text { supplier's enterprise financial index } \\
\text { R2 in the simulation }\end{array}$ & $(0,1)$ \\
\hline K3 & $\begin{array}{l}\text { Adjust the influence of the } \\
\text { supplier's internal index R3 in the } \\
\text { simulation }\end{array}$ & $(0,1)$ \\
\hline
\end{tabular}

\subsection{Analysis of supply chain simulation results based on multi agent characteristics}

A variety of indicators are introduced into the simulation evaluation of the supply chain, and five product types are set respectively (common product, unqualified product, flexible preference product, quality preference product and cost preference product). According to the data processing of supply chain, market research and the change of research value, the simulation parameters are set by percentage system. The detailed algorithm is shown in Table 2 and table 3

Table 2. Parameter setting table of supplier satisfaction evaluation.

\begin{tabular}{|c|c|c|c|}
\hline $\begin{array}{c}\text { Symb } \\
\text { ol }\end{array}$ & $\begin{array}{c}\text { Parameter } \\
\text { name }\end{array}$ & $\begin{array}{c}\text { Value range / } \\
\text { calculation formula }\end{array}$ & Weight \\
\hline SC & $\begin{array}{c}\text { Enterprise } \\
\text { scale }\end{array}$ & random-normal 50 30 & 0.4 \\
\hline IPO & Listing & $\begin{array}{c}\text { If SC }>85, \\
\text { IPO=100; } \\
\text { Else IPO=0 }\end{array}$ & 0.1 \\
\hline DIS & Distance & random-normal 70 30 & 0.5 \\
\hline TOR & $\begin{array}{c}\text { Return on net } \\
\text { assets } \\
\text { turnentory }\end{array}$ & random-normal 70 20 & 0.6 \\
\hline ODR & $\begin{array}{c}\text { Order delivery } \\
\text { rate }\end{array}$ & random-normal S- & 0.5 \\
\hline FLEX & $\begin{array}{c}\text { Urgent order } \\
\text { completion } \\
\text { rate }\end{array}$ & random-normal 60 20 & 0.2 \\
\hline COST & $\begin{array}{c}\text { Total cost of } \\
\text { supply } \\
\text { management }\end{array}$ & random-normal 60 30 & 0.3 \\
\hline
\end{tabular}

\begin{tabular}{|c|c|c|c|}
\hline PQR & $\begin{array}{c}\text { Product } \\
\text { qualification } \\
\text { rate }\end{array}$ & random-normal 95 5 & $\begin{array}{c}1-\mathrm{K} 1- \\
\mathrm{K} 2-\mathrm{K} 3\end{array}$ \\
\hline $\mathrm{S}$ & $\begin{array}{c}\text { Supplier } \\
\text { satisfaction }\end{array}$ & $\begin{array}{c}\mathrm{K} 1 * \mathrm{R} 1+\mathrm{K} 2 * \mathrm{R} 2+\mathrm{K} 3 * \mathrm{R} 3+(1-\mathrm{K} 1- \\
\mathrm{K} 2-\mathrm{K} 3) * \mathrm{PQR}\end{array}$ \\
\hline
\end{tabular}

Table 3. Customer satisfaction evaluation parameter setting table.

\begin{tabular}{|c|c|c|}
\hline $\begin{array}{c}\text { Symb } \\
\text { ol }\end{array}$ & Parameter name & $\begin{array}{c}\text { Value range } / \\
\text { calculation formula }\end{array}$ \\
\hline PERF & Customer preference & $\begin{array}{c}\text { random-normal } 0.5 \\
0.3\end{array}$ \\
\hline \multirow{2}{*}{} & $\begin{array}{c}\text { Enterprise flexibility } \\
\text { preference }\end{array}$ & $0<=\mathrm{PREF}<0.2$ \\
\cline { 2 - 3 } & Product quality preference & $0.2<=\mathrm{PREF}<0.4$ \\
\cline { 2 - 3 } & Low cost preference & $0.7<=\mathrm{PREF}<1$ \\
\cline { 2 - 3 } & No special preference & $0.4<=\mathrm{PREF}<0.7$ \\
\hline \multirow{2}{*}{$\mathrm{S}$} & Customer satisfaction & random-normal 8510 \\
\hline
\end{tabular}

Set when the flexibility of suppliers and enterprises is better (Flex $>90$ ), produce products (light blue) that customers need. When $0 \leq$ pref $<0.3$ is judged, if the customer prefers the enterprise with better flexibility, when the customer receives the product with flexible preference (light blue), the added value of satisfaction is higher than that of ordinary product (green).

When the qualified rate of $\mathrm{T}$ products of suppliers and enterprises is high $(\mathrm{PQR}>100)$, the products (pink) required by customers with quality preference will be produced. When the judgment is $0.3 \leq$ pref $<0.6$, the customer prefers the enterprise with better product quality. When the customer receives the product with better product quality (pink), the added value of satisfaction is higher than that of ordinary product (green).

When the financial status of suppliers and enterprises is good ( R2 > 90) and the cost of supply chain management is low (cost $>90)$, they can produce products (yellow) with low cost preference for customers. When the judgment is $0.6 \leq$ pref $<1$, if the customer prefers the enterprise with lower supply chain management cost and better financial status, when the customer receives the product with lower cost (yellow), the added value of satisfaction is higher than that of ordinary product (green).

At this time, the preferences of suppliers and customers are random.

Set the number of suppliers and customers as 25 and 50 , tolerance for unqualified products are 0 and delivery rate are $100 \%$, and the coefficients $\mathrm{K} 1, \mathrm{~K} 2$ and $\mathrm{K} 3$ are 0.25 , that is, the four types of indicators of supply chain satisfaction occupy the same weight. The simulation results are as follows: 


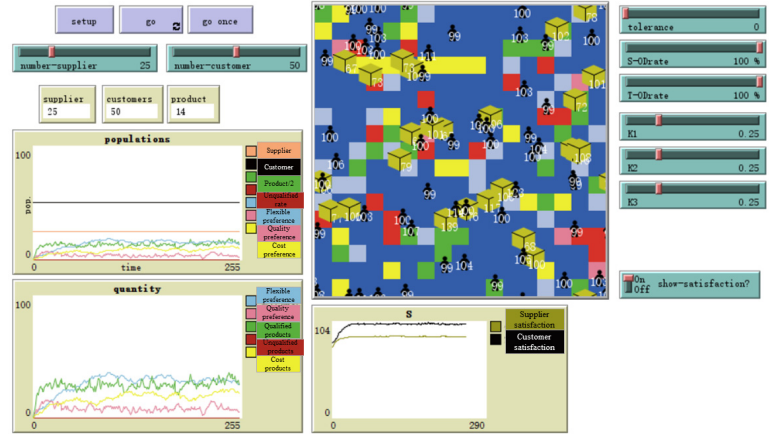

Fig. 4. Simulation results when K1, K2 and K3 are all 0.25 .

It can be seen that under the current conditions, the number of surplus products of flexible preference and ordinary products is in the majority, the number of several products fluctuates stably, and the satisfaction of suppliers and customers is stable.

When other conditions remain unchanged and only $\mathrm{K} 1, \mathrm{~K} 2$ and $\mathrm{K} 3$ values are changed, the differences of drawing graphics are compared under the same time scale.

Set $\mathrm{K} 1$ to 1.0 and $\mathrm{K} 2$ and $\mathrm{K} 3$ to 0 , that is, when supplier satisfaction is only affected by enterprise basic information indicators, the simulation results are shown in Figure 5-6 (a).

Set $\mathrm{K} 2$ to 1.0 and $\mathrm{K} 1$ and $\mathrm{K} 3$ to 0 , that is, when supplier satisfaction is only affected by enterprise financial indicators, the simulation results are shown in Figure 5 below.
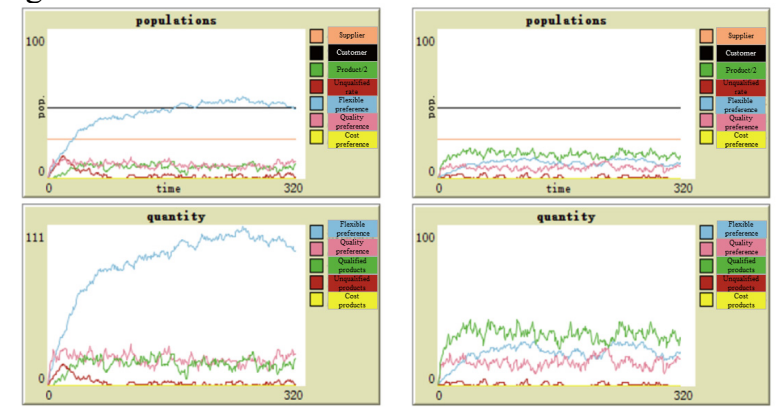

Fig. 5. Only the graph when $\mathrm{K} 1$ and $\mathrm{K} 2$ are changed.

Set $\mathrm{K} 3$ to 1.0 and $\mathrm{K} 1$ and $\mathrm{K} 2$ to 0 , that is, when the supplier satisfaction is only affected by the internal indicators of the enterprise, the simulation results are shown in Figure 6.

Set $\mathrm{K} 1, \mathrm{~K} 2$ and $\mathrm{K} 3$ to 0 , that is, when supplier satisfaction is only affected by product qualification rate, the simulation results are shown in Figure 6 below.
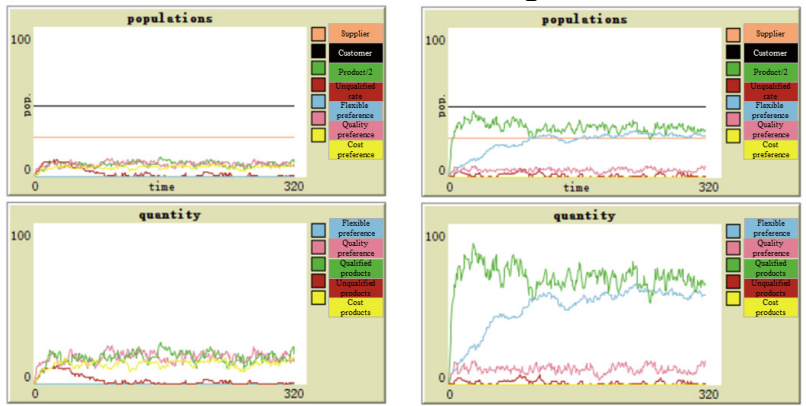

Fig. 6. Only change the graph when $\mathrm{K} 3$ value is taken.

From Figure 5 and Figure 6, it can be seen that when the preferences of suppliers and customers are random, the satisfaction evaluation criteria of suppliers have

some influence on them. When the supplier satisfaction is only affected by the enterprise basic information index (R1), the flexible preference for surplus products in the market is at a higher level; when the supplier satisfaction is only affected by the enterprise financial index (R2), the surplus products in the market as a whole are at a relatively balanced level; when the supplier satisfaction is only affected by the enterprise internal index (R3), the surplus products in the market are at a lower level When the supplier satisfaction is only affected by the product qualification rate $(\mathrm{PQR})$, the level of common goods and flexible preference surplus products in the market is higher, and the total is higher than the supply chain coordination level, showing a trend of supply exceeding demand.

Then observe the change of supplier and customer satisfaction under Figure 7.

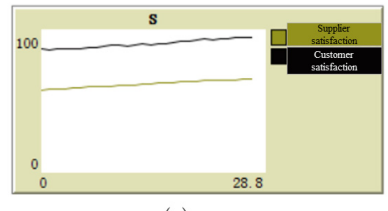

(a)

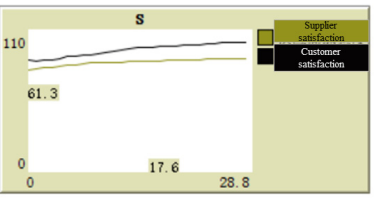

Fig. 7. Satisfaction graph of K1, K2 and K3 changes.

It can be seen that, due to the design of supplier satisfaction algorithm, when $\mathrm{K} 1$ is $1, \mathrm{~K} 2$ and $\mathrm{K} 3$ are 0 , the initial level of satisfaction is low, about 63; when K2 is $1, \mathrm{~K} 1$ and $\mathrm{K} 3$ are 0 , the satisfaction level is moderate, about 78; when $\mathrm{K} 3$ is $1, \mathrm{~K} 1$ and $\mathrm{K} 2$ are 0 , the satisfaction level is moderate, about 80 ; when $\mathrm{K} 1, \mathrm{~K} 2$ and $\mathrm{K} 3$ are 0 , the satisfaction level is relatively high, about 86 . That is, the initial level of satisfaction of suppliers has an impact on the quantity of remaining products in the market. When the initial level of satisfaction of suppliers is higher, the more common products are left in the market, the more different preferences of customers can meet.

According to the supply chain data provided by enterprise $T$, the number of suppliers is 26 , the number of customers is 47 , the delivery rate of supplier orders is $85.2 \%$, the delivery rate of enterprise t-order is $99 \%$, and the weighted coefficient of supplier satisfaction $\mathrm{K} 1, \mathrm{~K} 2$ and $\mathrm{K} 3$ are set to be 0.25 . The simulation results are shown in the figure below:

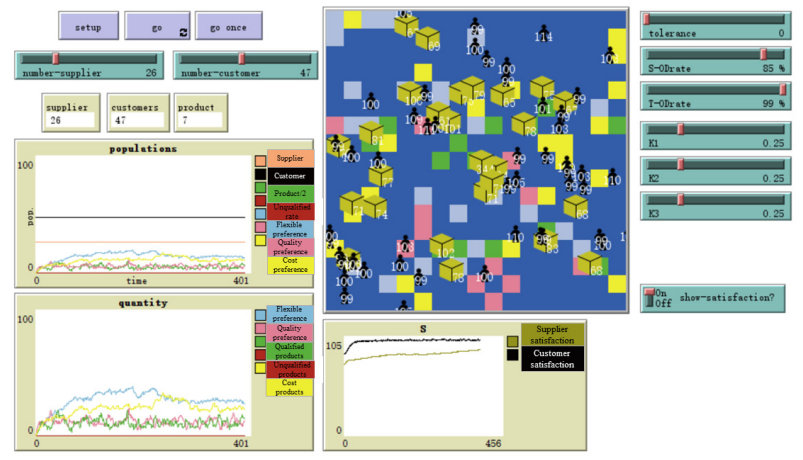

Fig. 8. Simulation of enterprise real data supply chain. 
It can be seen that in this case, there are different types of products in the market with different customer preferences, and the quantity of four products except non-conforming products is not different, and the number of flexible preference products is the most remaining in the simulation. Because of the randomness of supplier and customer preference, the remaining product level is maintained at a lower level after many tests, which is basically the same as the set supply chain coordination state.

- 10-point Times, Times Roman or Times New Roman.

- The text should be set to single line spacing.

- Paragraphs should be justified.

- The first paragraph after a section or subsection should not be indented; subsequent paragraphs should be indented by $5 \mathrm{~mm}$.

The use of sections to divide the text of the paper is optional and left as a decision for the author. Where the author wishes to divide the paper into sections the formatting shown in Table 3 should be used.

Table 3. Formatting sections, subsections and subsubsections.

\begin{tabular}{|c|c|c|c|}
\hline & Font & Spacing & Numbering \\
\hline Section & $\begin{array}{c}\text { 12-point } \\
\text { Arial bold }\end{array}$ & $\begin{array}{c}6 \mathrm{~mm} \text { before } \\
3 \mathrm{~mm} \text { after }\end{array}$ & $1,2,3$, etc. \\
\hline subsection & $\begin{array}{c}10 \text {-point } \\
\text { Arial bold }\end{array}$ & $\begin{array}{c}6 \mathrm{~mm} \text { before } \\
3 \mathrm{~mm} \text { after }\end{array}$ & $\begin{array}{c}1.1,1.2,1.3, \\
\text { etc. }\end{array}$ \\
\hline subsubsection & $\begin{array}{c}\text { 10-point } \\
\text { Arial Italic }\end{array}$ & $\begin{array}{c}6 \mathrm{~mm} \text { before } \\
3 \mathrm{~mm} \text { after }\end{array}$ & $\begin{array}{c}1.1 .1,1.1 .2, \\
1.1 .3, \text { etc. }\end{array}$ \\
\hline
\end{tabular}

\section{Suggestions on the optimization of enterprise $t$ supply chain}

The order delivery rate of enterprise $\mathrm{T}$ is very high, which is $99.0 \%$, while the average order delivery rate of the suppliers selected by enterprise $\mathrm{t}$ is only $85.2 \%$, which is not ideal. If other parameters remain unchanged, the supplier order delivery rate is set to $97 \%$ for simulation.

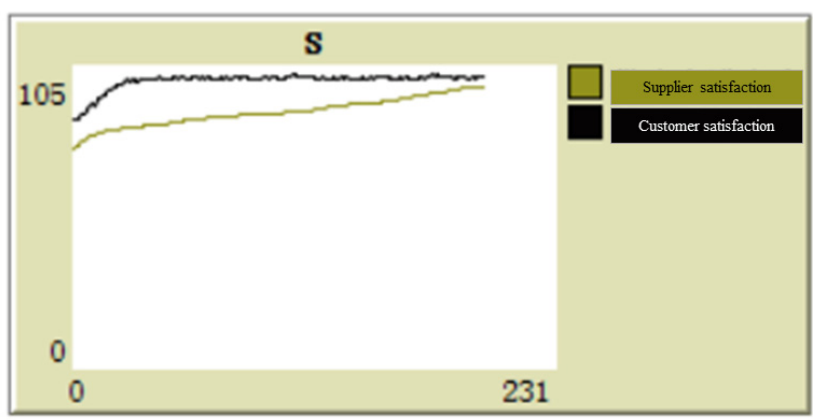

Fig. 9. Simulation graph when the delivery rate of supplier order is $97 \%$.

It can be seen that at this time, enterprise t's evaluation of supplier satisfaction will rise quickly, with a good level, which is conducive to supply chain management.

The basic information index R1 of supplier selected by enterprise $\mathrm{T}$ is low. If other parameters are set unchanged, the supplier with larger scale and closer to enterprise $t$ is selected (change the random generation range of SC and dis, as shown in Table 4), and the supplier satisfaction evaluation is completely affected by $\mathrm{R} 1(\mathrm{~K} 1=1)$, the simulation results are as follows:

Table 4. Parameter setting table after changing the random generation range of SC and DIS.

\begin{tabular}{|c|c|c|c|}
\hline Symbol & $\begin{array}{c}\text { Parameter } \\
\text { name }\end{array}$ & $\begin{array}{c}\text { Value range / } \\
\text { calculation } \\
\text { formula }\end{array}$ & Weight \\
\hline SC & Enterprise scale & $\begin{array}{c}\text { random-normal } \\
7020\end{array}$ & 0.4 \\
\hline IPO & Listing & $\begin{array}{c}\text { If SC }>85 \\
\text { IPO }=100 ; \\
\text { Else IPO=0 }\end{array}$ & 0.1 \\
\hline DIS & Distance & $\begin{array}{c}\text { random-normal } \\
8510\end{array}$ & 0.5 \\
\hline
\end{tabular}

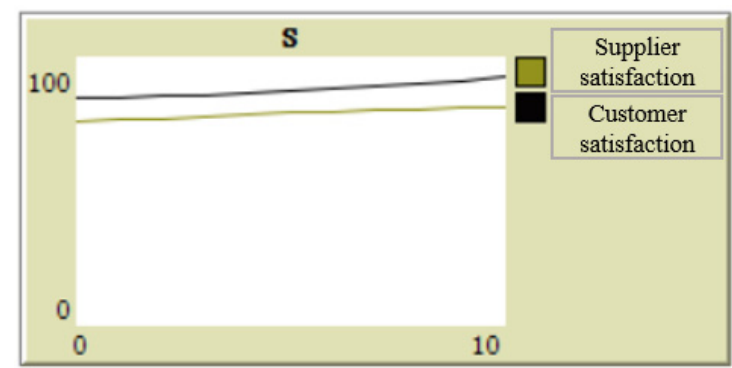

Fig. 10. Simulation graphics after increasing the value of R1.

It can be seen that after the adjustment, the value of $\mathrm{R} 1$ increases, and the starting value is about 77 , which is equivalent to the starting values of $\mathrm{R} 2$ and $\mathrm{R} 3$, which is conducive to improving the overall satisfaction level of suppliers.

\section{Conclusion}

In this paper, the main behavior simulation of supply chain is carried out by using netlogo software to suppliers and customers of enterprise T. Netlog is a multi-agent simulation software, which can set independent parameters and algorithms for multiple entities at the same time, and simulate its evolution process. Through simulation, the overall influence of the main body behavior difference on supply chain is investigated, so that it can better guide similar enterprises to provide the supply The continuous optimization of the chain should have theoretical and practical application value. However, the supply chain simulation system is still insufficient. Because of the imperfect internal data acquisition, the practicability of the simulation conclusion needs to collect more data related to the enterprise $t$ supply chain to verify.

\section{Acknowledgments}

The authors gratefully acknowledge the financial support from National Key R\&D Program of China (2018YFB1004004). 


\section{References}

1. Ma Shihua. On the influence of core enterprises on the formation of strategic partnerships in the supply chain [J]. Industrial Engineering and Management, 2000(01):24-27

2. Hu Kaishun, Yao Xiaoqun, Ye Bangyan, et al. The structure model and planning design of the dynamic alliance supply chain[J]. Mechanical Design and Manufacturing Engineering, 2003, 32(2): 73-75

3. Lee $\mathrm{H}$, Padmanabhan $\mathrm{V}$, Whang S. Information distortion in a supply chain: The bullwhip effect[J]. Management Science, 2004.12(50) 1887-1893

4. Zhao Wendan, Wang Dingwei. Research on Supply Chain Inventory Control Strategy [C]// China Chemical Industry Association Chemical Industry Automation and Instrumentation Committee Academic Annual Meeting. 2010

5. $\mathrm{Xu}$ Chao. Research on Cooperative Procurement Negotiation Strategy of Cluster Supply Chain Based on Multi-Agent[D]. Hangzhou Dianzi University, 2019

6. Xue Ying. Research on inventory control strategy under supply chain environment[J]. Market Modernization, 2012(11):4-4

7. Yao Jianming. Supply chain operation analysis based on member target positioning under mass customization mode [J]. Business Economics and Management, 2013, 1(005): 13-21

8. Amin Aalaei; Hamid Davoudpour. A robust optimization model for cellular manufacturing system into supply chain management [J]. International Journal of Production Economics, 2017.1(183) 667-679

9. Behnam Karimi; Mahdi Bashiri. Designing a Multicommodity multimodal splittable supply chain network by logistic hubs for intelligent manufacturing. Procedia Manufacturing, 2018(17) 1058-1064

10. Antonio A. C. Vieira; Luís M. S. Dias;. Supply chain hybrid simulation: From Big Data to distributions and approaches comparison [J]. Simulation Modelling Practice and Theory, 2019.101956 